\title{
Desenvolvimento e montagem de VANT de asa fixa de baixo custo para suprir a demanda de ensino e pesquisa nas Geociências
}

\author{
DeVELOPMENT AND ASSEMBLY OF A LOW-COST FIXED-WING UAV tO SUPPLY THE DEMAND BY EDUCATION AND RESEARCH IN THE GEOSCIENCES \\ Leonardo Cardoso Renner ${ }^{1}$, Tatiana Silva da Silva² ${ }^{2}$ Cláudio Wilson Mendes Júnior ${ }^{2}$, Rodrigo Felipe Wiebbeluing ${ }^{3}$ \& Gabriel Augusto Breda 4 . \\ 1 - Departamento de Geodésia, Instituto de Geociências, Universidade Federal do Rio Grande do Sul. Av. Bento Gonçalves, Porto Alegre, RS, Brasil \\ 2 - Programa de Pós-graduação em Geociências, Departamento de Geodésia, Instituto de Geociências, Universidade Federal do Rio Grande do Sul. Av. Bento \\ Gonçalves, Porto Alegre, RS, Brasil \\ 3 - Graduando do Curso de Ciências da Computação, Instituto de Informática, Universidade Federal do Rio Grande do Sul. Av. Bento Gonçalves, Porto Alegre, RS, \\ BRASIL \\ 4 - Graduando do Curso de Geografia, Instituto de Geociências, Universidade Federal do Rio Grande do Sul. Av. Bento Gonçalves, Porto Alegre, RS, Brasil

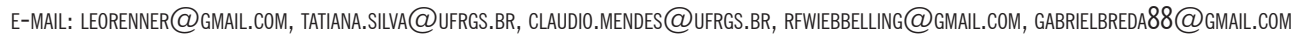

Abstract: This paper presents the assembly and development of a low-cost Skywalker X8 fixed-wing (UAV) platform for education and research. The use of these platforms for civil use has gained prominence in the last decade, due to the growing demand for mapping, monitoring, imaging, inspection, among others, driven by countries such as Brazil and Canada. This paper recommends some structural modifications that demonstrated a significant improvement in the performance of this platform, besides cost reduction. The selection of the type of electric motor, propeller, battery, communication channel, telemetry, and flight controller, followed a technical study aimed at increasing the range of possible data acquisition areas in the geosciences. The result was the development of a UAV costing approximately US $\$ 4,070.00$, a cost that is lower than the one offered in the market.

Resumo: Este trabalho apresenta a montagem e o desenvolvimento de uma plataforma (VANT) de asa fixa, modelo Skywalker X8 de baixo custo destinado ao ensino e pesquisa. A utilização destas plataformas para uso civil tem se destacado na última década, devido à crescente demanda por dados de mapeamento, monitoramento, imageamento, inspeção, entre outros, impulsionados por países como 0 Brasil e 0 Canadá. Este trabalho recomenda algumas modificações estruturais que demonstraram um aperfeiçoamento significativo no desempenho desta plataforma, além da redução do seu custo. A seleção do tipo de motor elétrico, hélice, bateria, canal de comunicação e telemetria e a controladora de vo0, seguiu um estudo técnico voltado para aumentar 0 leque de possíveis áreas de obtenção de dados nas geociências. 0 resultado foi o desenvolvimento de um VANT custando aproximadamente $U \$ 4.070,00$, um custo inferior ao oferecido no mercado.
Citation/Citação: Renner, L. C.; Silva, T. S.; Mendes Júnior, C. W.; Wiebbelling, R. F.; Breda, G. A. (2020). Desenvolvimento e montagem de VANT de asa fixa de baixo custo para suprir a demanda de ensino e pesquisa nas Geociências. Terræ Didatica, 16, 1-12, e020002. doi: 10.20396/td.v16i0.8655049.

Keywords: UAV, Fixed wing platform, Skywalker X8, Pixhawk.

Palavras-chave: Veículos Aéreos Não Tripulados (VANT), Plataforma de asa fixa, Skywalker X8, Pixhawk.

Manuscript/Manuscrito:

Received/Recebido: 28/03/2019

Revised/Corrigido: 01/10/2019

Accepted/Aceito: 29/01/2020

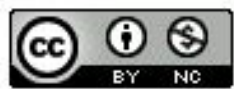

\section{Introdução}

Os Veículos Aéreos Não Tripulados (VANT), mais conhecidos popularmente como drones, compreendem plataformas que podem ser remotamente pilotadas (Remotely Piloted Aircraft), conforme definido pela International Civil Aviation Organization (ICAO) ou SISVANT (Sistema de Veículo Aéreo não Tripulado) em Português.

As plataformas VANT podem ser de asa fixa ou rotativa, balões estacionários e dirigíveis. $\mathrm{O}$ uso da plataforma de asa fixa possui grandes vantagens em relação às demais plataformas, tais como: maior velocidade de voo, maior cobertura de área, maior segurança, baixo consumo de bateria, maior capacidade de carregar equipamentos, maior tempo de voo e baixo custo de fabricação e manutenção.

Estas plataformas mostraram na última década serem uma ferramenta importante na obtenção de dados nas diversas áreas das geociências. Suas aplicações civis vão desde o mapeamento topográfico e geológico, monitoramento de fauna e incêndios, segurança pública, inspeção e avaliação industrial e elétrica, gerenciamento urbano, imageamento etc.

Países como os Estados Unidos, Israel e China são líderes no desenvolvimento de plataformas VANT para uso militar. Atualmente países mem-

\begin{tabular}{c|c|c|c|c|c}
\hline (C) Terrae Didat. & Campinas, SP & v.16 & $1-12$ & $\mathrm{e} 020002$ & 2020 \\
\hline
\end{tabular}


bros da comunidade europeia e americanos (destaque para o Brasil e Canadá) desenvolvem estas plataformas principalmente para uso civil, cuja demanda é crescente neste setor.

No Brasil o custo para a obtenção de um VANT comercial no ano de 2011 ficava em torno de US $\$ 30.000$ e se limitava a poucas empresas nacionais. Estas plataformas eram essencialmente de asa fixa e foram desenvolvidas com o emprego de equipamentos eletrônicos caros e complexos, necessitando de um amplo conhecimento técnico para a sua fabricação.

Este cenário mudou a partir do ano de 2013 com o desenvolvimento de eletrônicos mais baratos e com melhor poder de processamento. Portanto, possibilitando a construção destas plataformas por um público menos técnico. Neste contexto, novos produtos foram lançados no mercado, os chamados open hardware e open software que baixaram os preços das controladoras de voo (cérebro da plataforma) no mercado internacional e isso gerou o desenvolvimento de constantes atualizações e aperfeiçoamento até o presente momento.

A aplicação e validação dos dados gerados por essas plataformas no Brasil foram demonstradas inicialmente por trabalhos publicados por Medeiros (2007) e Longhitano (2010).

Existem diversos modelos de plataformas de asa fixa utilizados em pesquisa científica, além do modelo proposto neste trabalho, com destaque para o modelo Skyhunter (Fig. 1) utilizado em mapeamento e quantificação de pilhas de rejeitos em mineração (Renner et al., 2014) e também utilizado conjuntamente com o modelo X8 para monitoramento e mapeamento de áreas de preservação ambiental (Madhavan et al., 2018).

Cada modelo possui características específicas como tempo de voo, alcance, resistência, envergadura, peso, material, capacidade de carga e preço que devem ser considerados no momento da escolha. Neste trabalho não serão abordadas comparações técnicas de cada modelo e sim uma metodologia de montagem e aperfeiçoamento técnico da plataforma Skywalker X8 para realização de levantamentos e pesquisa.

\section{Seleção da plataforma}

A plataforma Skywalker X8 foi selecionada devido ao seu fácil manuseio, montagem, corpo central amplo, e asas que podem ser facilmente desmontadas e transportadas. Esta plataforma uti-

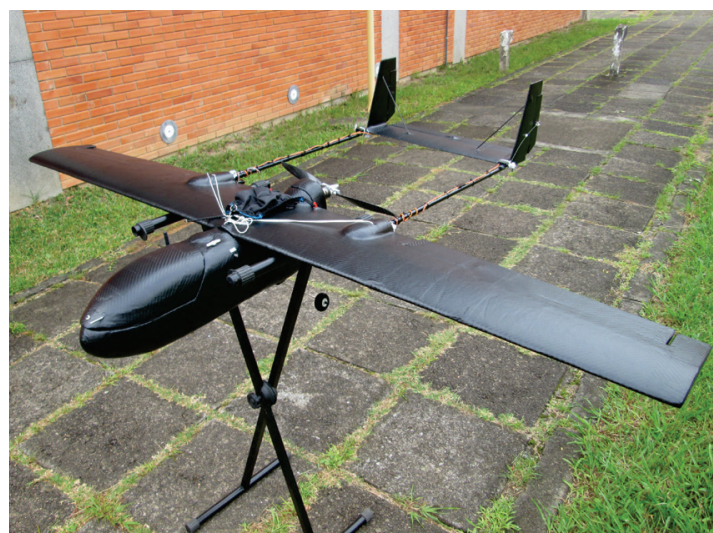

Figura 1. Plataformas de asa fixa modelo Skyhunter (180 cm de envergadura) com revestimento em vinil preto

liza uma velocidade de cruzeiro em torno de 70 $\mathrm{km} / \mathrm{h}$ e pode abranger em um único voo cerca de 10.000 ha. O Skywalker X8 possui envergadura de $2,122 \mathrm{~m}$, comprimento de $75 \mathrm{~cm}$, altura de $15 \mathrm{~cm}$, área de asa de $80 \mathrm{dm} 2$ e carga útil de 1000-2000 g. Seu kit de montagem possui um peso aproximado de $880 \mathrm{~g}$ e é composto por poliolefina expandida (Expanded Polyolefin) branco ou preto, conforme mostrado na figura 2. O EPO é um material termoplástico moldado, comumente utilizado em aeromodelos, sendo durável, forte e resistente a impactos, podendo voltar a sua forma original. Esta plataforma na forma de kit vem desmontada, necessitando portando, de no mínimo, 3 horas para a sua montagem primária.

Por se tratar de um avião em forma de asa em delta, esta plataforma pode movimentar-se em dois dos seus três eixos em relação ao seu centro

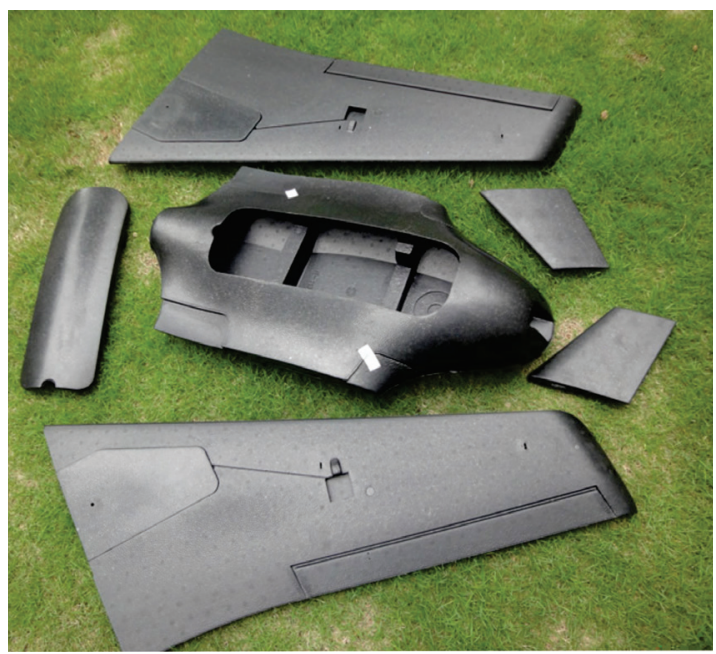

Figura 2. Plataforma de asa fixa modelo Skywalker $\mathrm{X} 8 \mathrm{em}$ kit para montagem

\begin{tabular}{c|c|c|c|c|c|}
\hline C Terrae Didat. & Campinas, SP & v.16 & $1-12$ & e020002 & 2020 \\
\hline \multicolumn{2}{|c|}{2}
\end{tabular}


de gravidade. As superfícies de comando dos dois ailerons/profundores controlam o ângulo de rolamento $(\phi)$ inclinação para a esquerda e direita e o ângulo de inclinação $(\theta)$ para cima ou para baixo. Esta plataforma não possui controle de leme, portanto não possui controle de guinada lateral $(\psi)$ esquerda e direita.

\section{Componentes integrantes da plataforma Skywalker X8}

Para que a plataforma de asa fixa seja operacional, é preciso a integração de componentes de hardware e software. Os componentes de hardware são compostos pela estrutura física externa (corpo e asas da aeronave), motor, hélice, servos de comando, bateria, controladora de voo, telemetria, receptor do rádio transmissor, receptor GNSS e sensor de velocidade e pressão do ar. Os softwares envolvidos na operação de voo são relacionados a telemetria e a ajustes do controle de voo remotamente configurados. A inoperância ou erro em qualquer um destes hardwares e/ou softwares pode comprometer a segurança e a execução do voo.

\section{Motor elétrico}

Foi utilizado o motor elétrico brushless outrunner modelo Turnigy L4255-500 de produção descontinuada, (Hobbyking, 2018) de $1100 \mathrm{~W}, 500$ $\mathrm{kV}(\mathrm{rpm} / \mathrm{V})$, corrente máxima de $49 \mathrm{~A}, 8 \mathrm{~mm}$ de diâmetro de eixo e peso de 263 g (Fig. 3). Este motor funciona com baterias de $22.2 \mathrm{~V}(6 \mathrm{~S})$ e tem capacidade de tração estática de $4500 \mathrm{~g}$.

Devido a não produção do motor acima citado é sugerida a utilização do modelo brushless outrunner Turnigy PROPDRIVE v2 4258 de 1256 W, 500 kV, corrente máxima de 60 A, $5 \mathrm{~mm}$ de diâmetro de eixo e peso de $300 \mathrm{~g}$, podendo funcionar com baterias LiPo de 4 ou $6 \mathrm{~S}$ gerando tração estática de até $5000 \mathrm{~g}$.

\section{Hélice}

A plataforma X8 possui o conjunto hélice/motor na parte traseira, ou seja, atrás do centro de gravidade (CG)

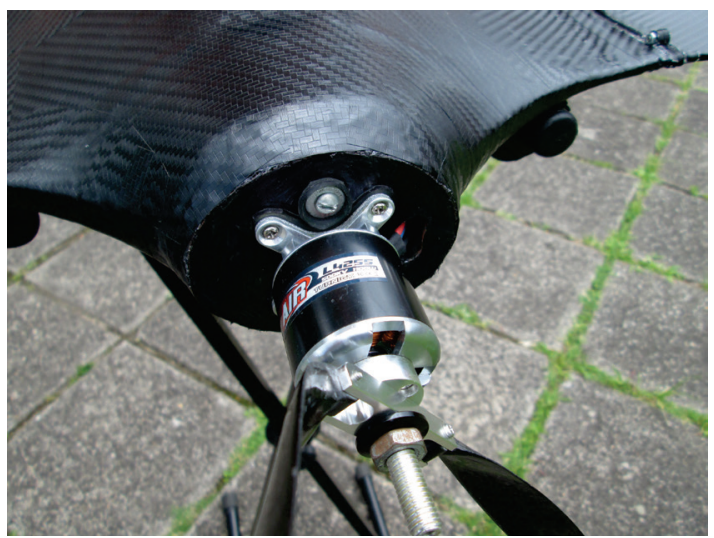

Figura 3. Motor elétrico Turnigy L4255-500 conectado na plataforma $\mathrm{X} 8$

da plataforma. A hélice nesta posição empurra o ar para traz impulsionando a aeronave para frente em situação de voo. As características da hélice são relacionadas ao seu tamanho, passo, quantidade de pás, forma e composição do material. Quanto ao seu tamanho a escolha da hélice deve ser proporcional a sua plataforma, neste caso, os tamanhos das hélices utilizadas para a plataforma X8 foram de 12, 14 e 15 centímetros (Fig. 4). O passo pode ser definido como a distância percorrida em uma única rotação. Quanto maior o passo, tanto menor será a rotação, mas irá aumentar a velocidade, usando mais energia. Foram utilizadas hélices com passo de 6 a 10 polegadas. As hélices usadas são de duas pás opostas que podem ser fixas ou dobráveis. Foi adotado preferencialmente o modelo de hélice dobrável, pois a plataforma X8 possui pouso de barriga e, sendo as hélices dobráveis, se evita danos a elas no momento do pouso, além de diminuir $\mathrm{o}$ arrasto em voo quando o motor não está sendo usado. O material da hélice pode ser de fibra de carbono ou de plástico.

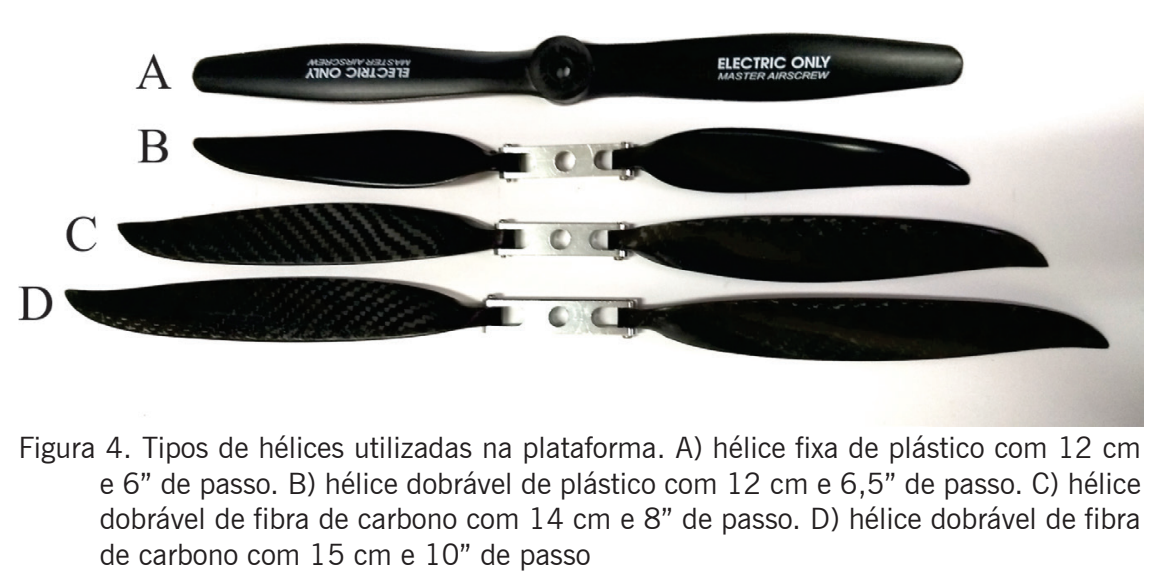




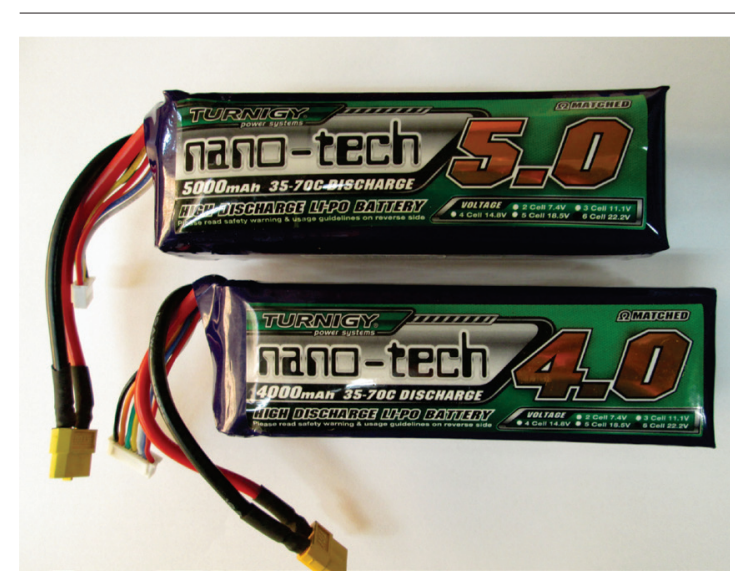

Figura 5. Baterias LiPo 6S utilizadas

\section{Baterias}

As baterias utilizadas são de polímero de lítio (LiPo - Lithium Polymer) e possuem 22.2 V, sendo equivalente a $6 \mathrm{~S}$ (cada $\mathrm{S}$ corresponde a uma célula de 3,7 V). As capacidades das baterias usadas variam entre 4000 a $5000 \mathrm{mAh}$ (mili-Ampere per hour) e a taxa de descarga (discharge rate) estimada entre 35 C (descarga contínua) a $70 \mathrm{C}$ (descarga rápida), conforme mostrado na figura 5 .

A plataforma possui autonomia média de 30 minutos para a plataforma pronta para o voo, com peso total bruto em $5,5 \mathrm{~kg}$ em uma única bateria de $5000 \mathrm{mAh}, 35-70 \mathrm{C}$ de descarga com $786 \mathrm{~g}$. O tempo de voo pode variar de acordo com o peso da plataforma, condições de vento, tipo de decolagem e velocidade de cruzeiro. A plataforma X8 possui espaço para transportar até duas baterias de $5000 \mathrm{mAh}$, (uma bateria na parte frontal e outra na parte central) tendo uma autonomia estimada de 50 minutos.

As configurações da bateria utilizada (quantidade e amperagem) são determinadas pelas características da missão como o tempo de voo, distância e a temperatura ambiente, uma vez que em temperaturas próximo a $0{ }^{\circ} \mathrm{C}$ as baterias de polímero de lítio perdem significativamente o seu desempenho. Quanto maior forem as amperagens das baterias maior será o seu peso o que não necessariamente irá refletir em um tempo de voo maior, de modo geral, é aumentado cerca de $40 \%$ de acréscimo no tempo de voo na adição de uma bateria semelhante, pois esta nova adição também irá refletir no aumento de peso da plataforma. Foi proposto por Traub (2016) que em voo de cruzeiro a resistência máxima da bateria é alcançada quando o peso da(s) bateria(s) representa menos que $2 / 3$ do peso total da plataforma.

\section{Carregador/balanceador de baterias}

As baterias LiPo necessitam de carregadores com características especiais. Este carregador precisa ter a opção de carregamento de forma balanceada para evitar que alguma célula fique com uma voltagem diferente das demais. Baterias com células balanceadas fornecem o mesmo rendimento tendo suas cargas reduzidas simultaneamente com o seu uso.

Os carregadores possuem micro-controladores que monitoram o tempo máximo de carregamento, desligando-o quando este tempo é atingido. Possuem a função de carregamento com balanceamento, carregamento normal, descarregamento e armazenamento.

Quando carregamos e descarregamos uma bateria dizemos que ela passou por um "ciclo". As baterias LiPo possuem um limite máximo de ciclos, que podem variar de acordo com a amperagem utilizada ao carregar, qualidade do fabricante e armazenamento, suportando em média 400 ciclos.

O carregador utilizado foi o modelo Turnigy Reaktor que possui a função carregar/balancear/ descarregar de até duas baterias simultaneamente $(2 \times 300 \mathrm{~W})$, conforme mostrado na figura 6. Opera com baterias Li-ion, LiPo, LiFe, Ni-Cd, NiMH, LiHV, NiZN e Pb.

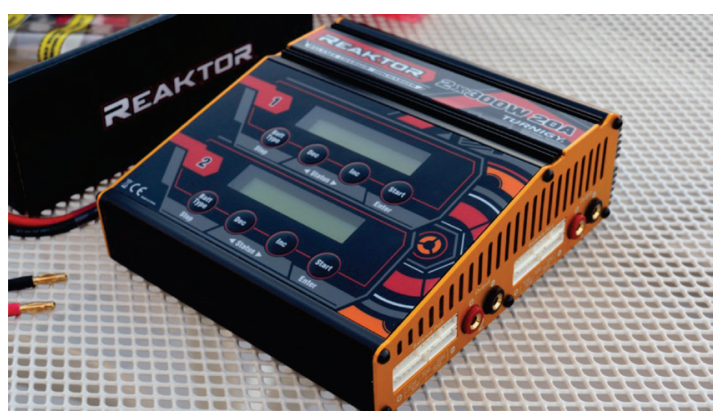

Figura 6. Carregador/balanceador modelo Turnigy Reaktor 2 x 300 W. Fonte: HobbyKing

\section{Rádio Transmissor (TX) e receptor (RX)}

O rádio transmissor é o equipamento que possibilita controlar a plataforma por meio de um receptor embarcado que decodifica o sinal gerado pelo transmissor e movimenta os servos para a movimentação da superfície de controle.

Foi adotado um rádio que pudesse ter dois módulos intercambiáveis, para curto e longo alcance. O rádio Turnigy 9X possui módulo de 2,4 GHz de frequência e receptor RX-9X8Cv2 de 8 canais de curto alcance, cerca de 2,5 km (Fig. 7). Para a utilização de comunicação de longo alcance foi adotado

\begin{tabular}{c|c|c|c|c|c}
\hline (C) Terrae Didat. & Campinas, SP & v.16 & $1-12$ & $\mathrm{e} 020002$ & 2020 \\
\hline
\end{tabular}




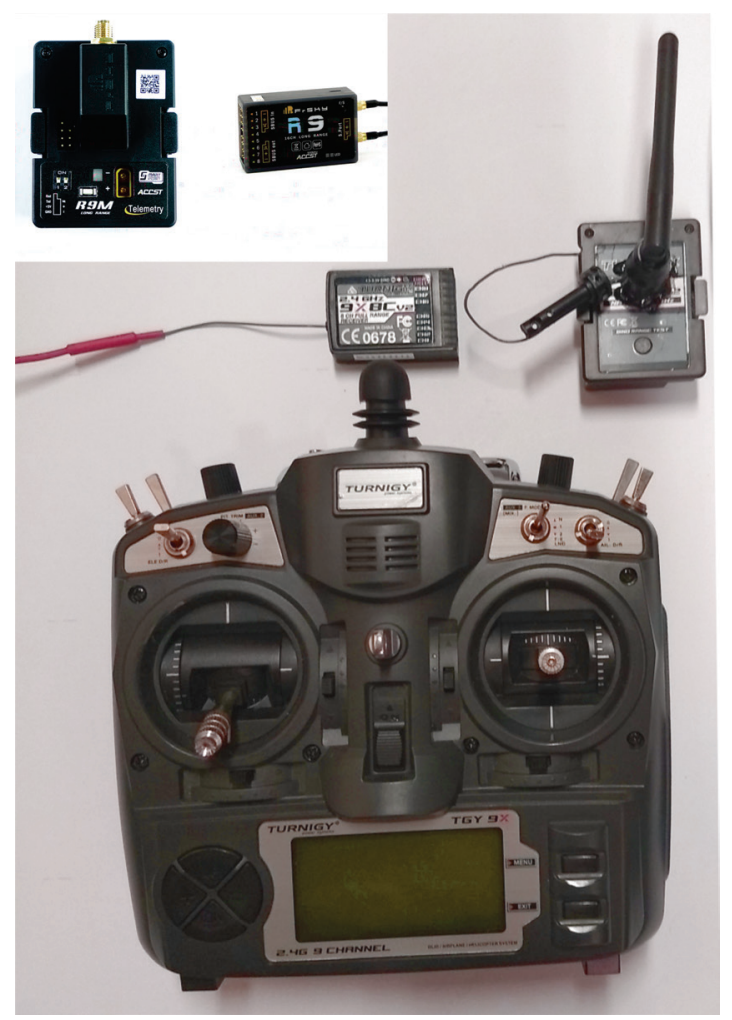

Figura 7. Rádio Turnigy 9X com módulo e receptor originais de curto alcance e módulo FrSky R9M e receptor $\mathrm{R} 9$

o mesmo rádio Turnigy 9X sem o módulo original de fábrica. O módulo utilizado foi o modelo FrSky R9M de 16 canais e potência entre 10 a $1000 \mathrm{~mW}$ com frequências entre 868 a $915 \mathrm{MHz}$ e o receptor 9R, podendo fornecer uma comunicação com a plataforma com uma distância máxima em visada aberta de $10 \mathrm{~km}$.

\section{ESC (Eletronic Speed Controllers)}

O ESC controla a velocidade do motor recebendo as informações por meio do receptor (RX) passando pela controladora de voo. São conectadas a bateria provendo $22,2 \mathrm{~V}$ para o motor e $5 \mathrm{~V}$ para a controladora, receptor e servos. Os modelos adotados foram Hobbyking Red Brick 70A e Turnigy AE-65A (Fig. 8).

\section{Controladora de voo}

Podemos dizer que a controladora de voo é o cérebro da plataforma. Pode controlar o voo de forma autônoma ou assistir de forma parcial o piloto por meio do processamento dos dados recebidos em tempo real pelos diversos sensores conectados, tais como: giroscópio, acelerômetro, barômetro, GPS, magnetômetro, câmera, etc.

Para a execução de um plano de voo com pontos pré-determinados a controladora no modo de piloto automático executa diversas rotinas, conforme proposto por Chao (2010):

1. Execução da altitude pré-determinada para cada ponto;

2. Manutenção desta altitude;

3. Manutenção da velocidade;

4. Nivelamento angular do voo;

5. Coordenação das curvas;

6. Manutenção da direção.

O tipo de controladora de voo influencia diretamente os tipos e modelos de sensores que podem ser embarcados. Por isso, foram adotados os modelos open hardware baseados na estrutura da Pixhawk, o que permite a sincronização dos sensores com as configurações propostas previamente no plano de voo. A versão 1.3.56 build 1.3.6672.30243 do software Mission Planner é compatível com as seguintes câmeras: Canon (S100-S110-S120, SX230HS, SX260-SX280, ELPH 520HS, ELPH 330HS, ELPH 115-130, A2300-A2400, 5D mk2; Nikon (aw100); Samsung s860, NX1000; FIREFLY 6S; Sony (A6000, A7R, A7R2), Nex5 25mm, Nex5 16mm, Nex7 16mm; Parrot Sequoia (Mono, RGB); WX 500; RedEdge; FLIR Vue (336 6,8-9$13 \mathrm{~mm}$ ) FLIR Vue (640 9-13-19mm); GoPro Hero 4 Black e AeroHawk 8MP.

A controladora adotada foi o modelo HKPilot32 de produção descontinuada e foi baseada no projeto da controladora Pixhawk 1. Possui um processador de 32-bit, $168 \mathrm{MHz}, 256 \mathrm{~KB}$ de RAM, sensor giros-
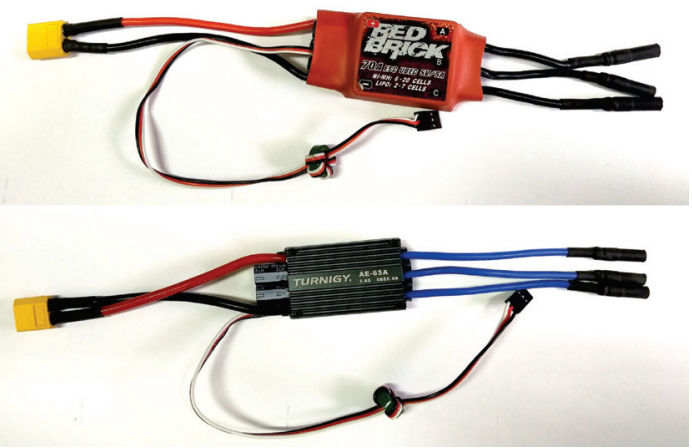

Figura 8. ESC Hobbyking Red Brick 70A e ESC Turnigy $A E-65 A$ 


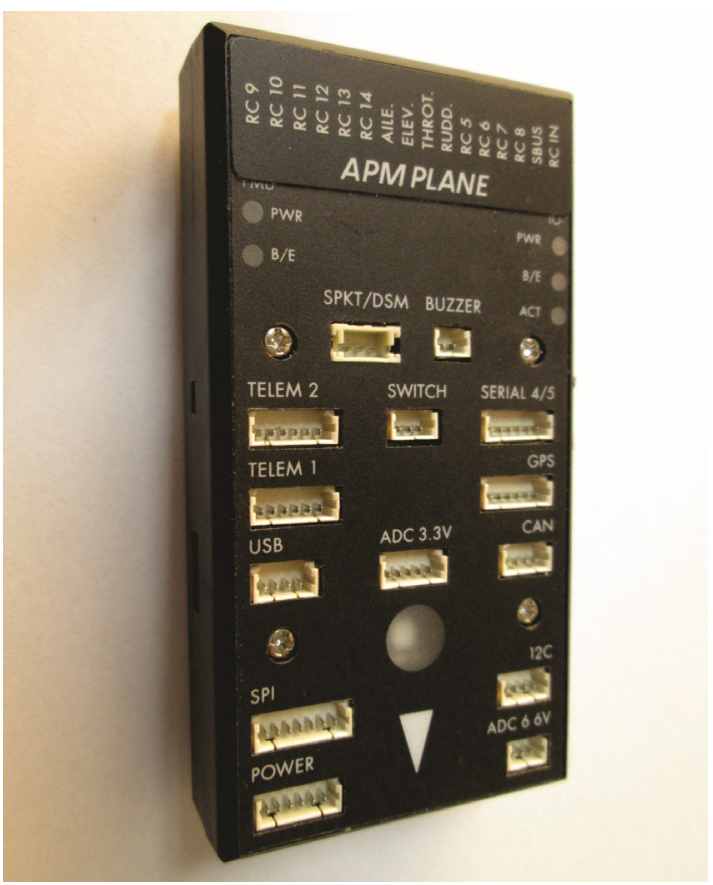

Figura 9. Controladora de voo modelo HKPilot32

cópio de 3 eixos, acelerômetro de 3 eixos, magnetômetro, barômetro e pesa 33,1 g. Possui entradas para a conexão do receptor (RX), conexão para o ESC, porta micro USB, entrada para os sensores de velocidade do ar, telemetria, GPS e sensores diversos, como câmeras RGB, câmeras termais, câmeras multi e hiperespectrais, LIDAR, RADAR, etc.

Devido à descontinuidade de produção desta controladora, é sugerida a substituição pelo modelo Pixhawk 4 de melhor processamento e fabricado pela Holybro®. Este modelo pesa somente 15,8 g, possui processador de 32-bit, $216 \mathrm{MHz}, 512$ KB de RAM, integrando sensores giroscópicos, acelerômetros, magnetômetros e barômetros mais modernos e duas entradas de baterias para sua alimentação de energia.

\section{Telemetria}

A telemetria é um sistema full-duplex de código aberto que possibilita o monitoramento e comandos em tempo real entre a plataforma e o operador em terra. Os dados da telemetria (altitude, velocidade, distância, direção, GPS, horizonte artificial, tipo de voo e mapa, entre outros) são visualizados pelo computador por meio do open software Mission Planner, mas pode ser usado também em celulares e tablets por meio do aplicativo 3DR Services.

Foram selecionados dois tipos de telemetria, uma de curto alcance e outra de longo alcance.

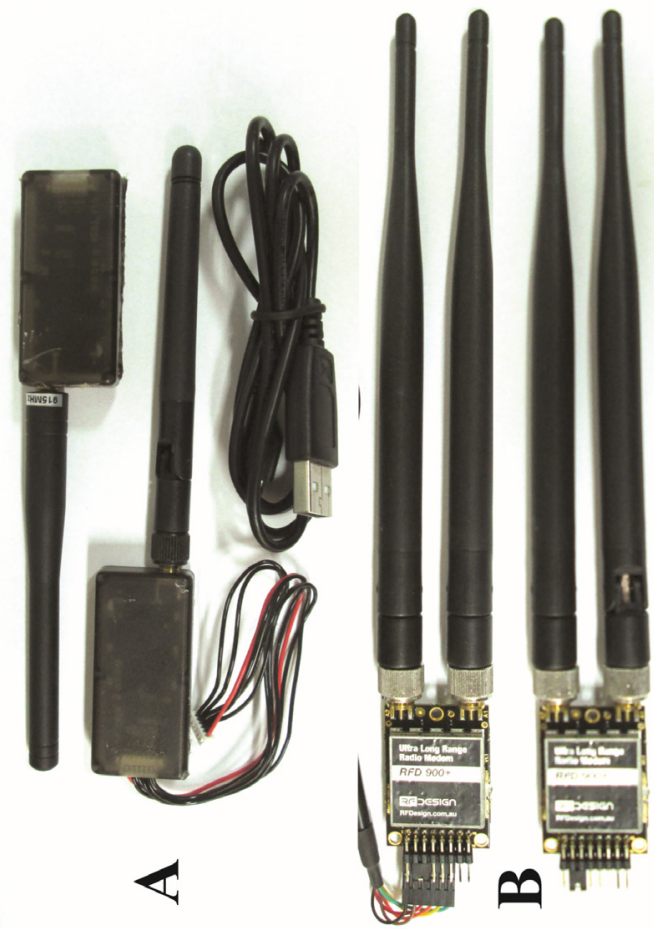

Figura 10. Modelos de telemetria utilizados. A) HKPilot de $915 \mathrm{MHz}$ de $100 \mathrm{~mW}$. B) RFD900+ de 900 $\mathrm{MHz}$ de $1000 \mathrm{~mW}$

A telemetria de curto alcance (até $3 \mathrm{~km}$ ) modelo HKPilot possui $915 \mathrm{MHz}$ de frequência e potência de $100 \mathrm{~mW}$ (Fig. 10). E a telemetria de longo alcance (até $40 \mathrm{~km}$ ) modelo RFD900+ possui 900 $\mathrm{MHz}$ de frequência e potência de $1000 \mathrm{~mW}$.

Ambas as telemetrias consistem em um kit de duas antenas omnidirecionais, na qual uma antena é conectada na controladora de voo da plataforma e a outra pode ser conectada no computador ou no celular/tablet.

\section{Receptor GNSS (Global Navigation Satellite System)}

O modelo adotado é o Ublox Neo-M8N, compatível para as controladoras baseadas na estrutura da Pixhawk, possui 72 canais, taxa de atualização de até $10 \mathrm{~Hz}$ possibilitando uma acurasse de velocidade em $0,05 \mathrm{~m} / \mathrm{s}$, acurasse de posicionamento horizontal em 2,5 m e bússola digital com acurasse de 0,3 graus. Os seus limites operacionais dinâmicos são de $\leq 4 \mathrm{~g}$, altitude em $50.000 \mathrm{~m}$ e de velocidade em $500 \mathrm{~m} / \mathrm{s}$. Sua temperatura operacional está entre $-40^{\circ}$ e $85^{\circ} \mathrm{C}$.

Este equipamento recebe os sinais das diversas constelações de satélites em órbita, tais como: GPS (L1C/A), GLONASS (L1OF), Galileo 
(E1B/C), BeiDou (B1) e QZSS (L1C/A), que são utilizados para calcular as coordenadas geodésicas (longitude, latitude e altitude geométrica) com precisão métrica em posicionamento absoluto.

O receptor está localizado dentro da asa esquerda da plataforma (Fig. 11). As informações são enviadas para a controladora de voo, que envia por telemetria a posição da plataforma, e que pode ser visualizada no software Mission Planner. Em modo de voo autônomo, as informações de posicionamento informam a plataforma para a execução do plano de voo, assim como a determinação do ponto de decolagem e de aterrissagem.

\section{Sensor de velocidade e pressão do ar}

Este equipamento possibilita a medição da velocidade do ar de até $100 \mathrm{~m} / \mathrm{s}$ com uma pressão máxima de 1 psi. Em conjunto com o sensor de temperatura e o barômetro interno da controladora de voo, este sensor pode calcular a velocidade real do ar com uma resolução de $0,84 \mathrm{~Pa}$. A parte externa deste sensor (tubo de Pitot) está localizada na frente da plataforma, conforme mostra a figura 12 , e possui uma entrada de ar frontal na qual mede a pressão dinâmica e três entradas laterais que medem a pressão estática, sendo a pressão total a soma da pressão estática e da pressão dinâmica.

\section{Sensores embarcados}

Devido a sua grande capacidade de carga, esta plataforma é muito versátil para o transporte de diferentes tipos de sensores, tendo a possibilidade de transportar até duas câmeras RGB e/ou infravermelho simultaneamente. Com pequenas modificações estruturais é possível transportar câmeras termais, multiespectrais, hiperespectrais, RADAR, LIDAR, entre outros sensores. A câmera utilizada para capturas de imagens RGB foi o modelo PowerShot S100 da Canon com 12,1 MP de resolução, para o qual foi necessária a atualização do firmware para a versão 1.1.0.0 provida pela Canon Hack Development Kit (CHDK). A figura 13 mostra a câmera Canon S100 dentro da plataforma para a aquisição de imagens.

\section{Servos}

São utilizados dois servos para movimentar a superfície de comando da plataforma, sendo um servo para cada asa, no modelo Hobbyking 939MG metal de 12,5 g (Fig. 14A). O servo utili-

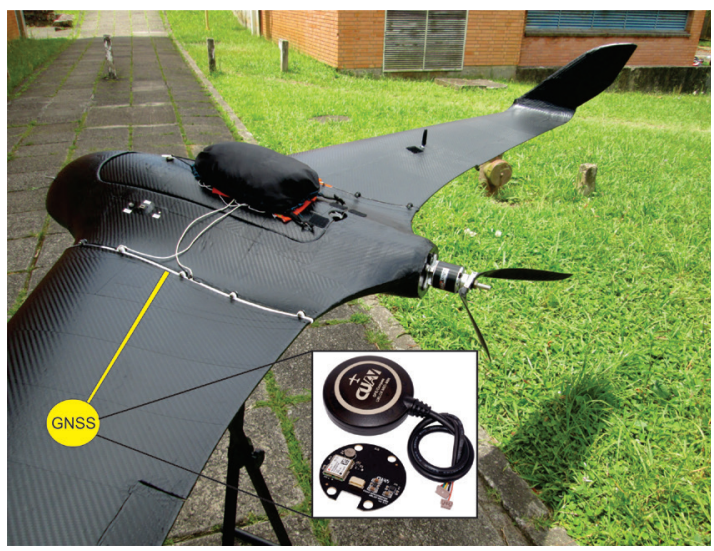

Figura 11. Receptor GNSS modelo Ublox Neo-M8M posicionado na asa da plataforma $\mathrm{X} 8$

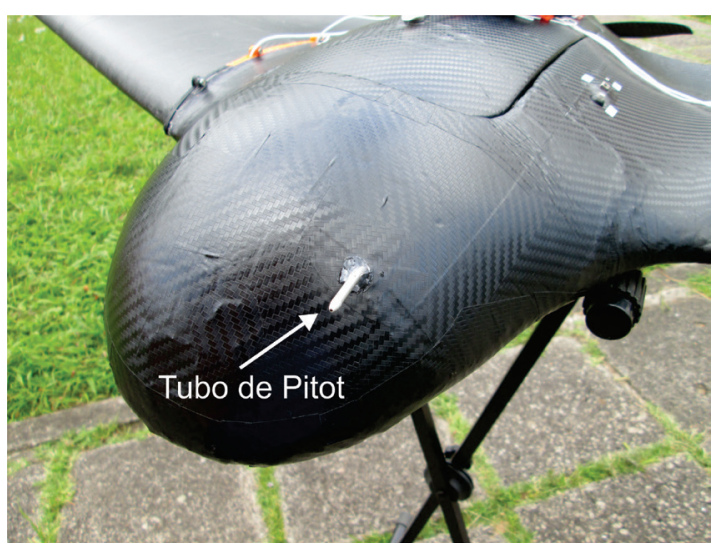

Figura 12. Componentes do sensor de velocidade e pressão do ar (tubo de Pitot) e sua localização na plataforma X8

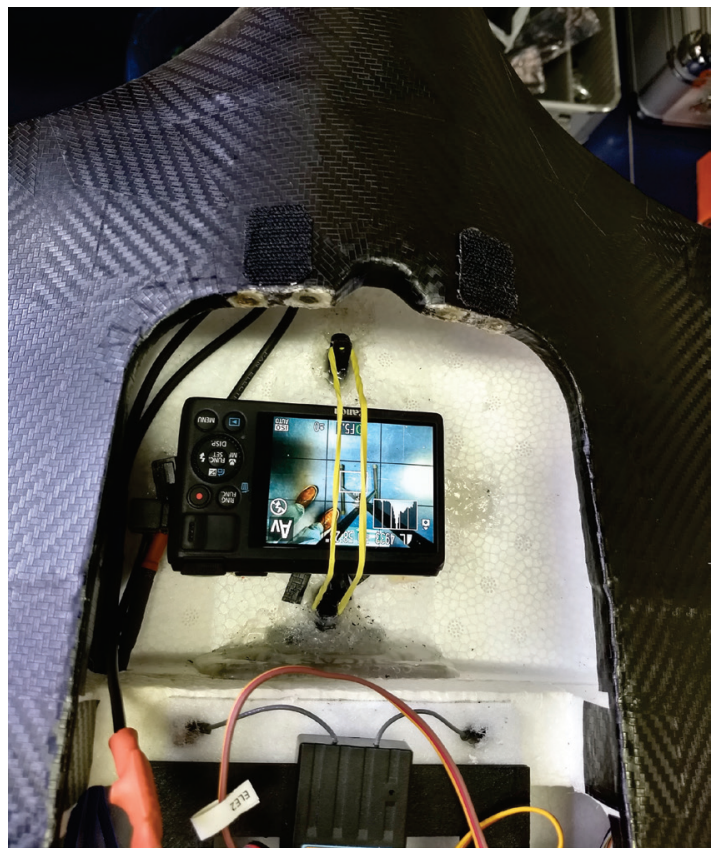

Figura 13. Câmera RGB Canon PowerShot S100 dentro do payload da plataforma X8 


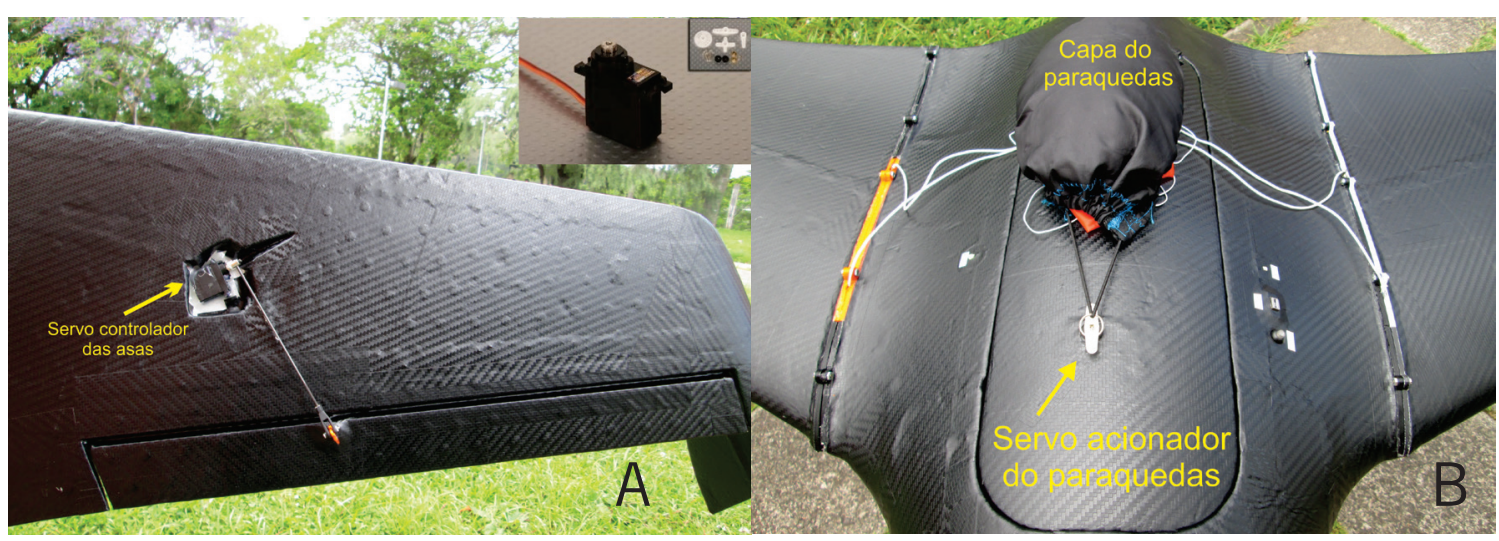

Figura 14. Servos de movimentação da asa e liberação do paraquedas. A) servo acionador das asas. Fonte: HobbyKing. B) servo acionador do paraquedas conectado ao paraquedas

zado para acionar o paraquedas é o modelo Corona DS339MG metal de 32 g. Este servo está situado na parte frontal superior da plataforma X8, conforme mostrado na figura 14B.

\section{Paraquedas}

A utilização de paraquedas pode prevenir danos no momento da aterrissagem da plataforma e também pode ser utilizado em resposta a problemas durante o voo, que necessitam da intervenção do piloto para aterrissagem em segurança. De acordo com o peso final da plataforma, são utilizados um dos dois modelos: de $3 \mathrm{~kg}$ ou de $5 \mathrm{~kg}$, possuindo raio de $0,95 \mathrm{~m}$ e $1,1 \mathrm{~m}$, respectivamente (Fig. 15). São elaborados em nylon e pesam entre 150 e $220 \mathrm{~g}$.

As duas barras estruturais de fibra de carbono da plataforma X8 foram utilizadas para a fixação das alças do paraquedas. Este paraquedas fica preso em uma capa de nylon situada na tampa central da plataforma e seu acionamento se dá por um servo controlado pelo rádio transmissor, conforme mostrado na figura 14B.

\section{Modificações recomendadas na montagem da estrutura}

A utilização de cola quente de silicone com aplicação por pistola aquecida mostrou-se ser eficiente e de baixo custo para colar as diversas partes da plataforma. O EPO possui boa aderência a esta cola. As peças de plástico fabricadas na impressora 3D, assim como as estruturas de fibra de carbono, também foram fixadas com a cola quente.

O corpo central possui duas partes, uma superior e uma inferior, sendo que a parte superior foi separada em três outras partes (centro, dianteira e

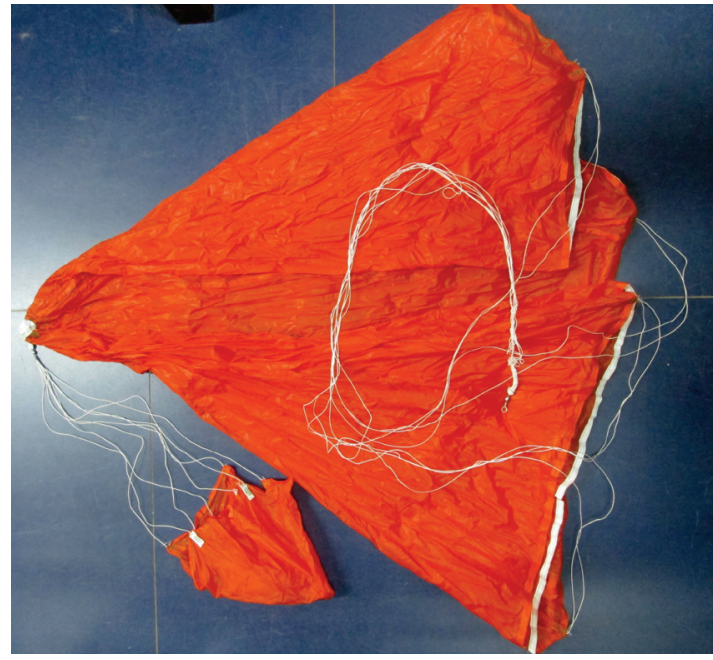

Figura 15. Paraquedas de $3 \mathrm{~kg}$ semiaberto no chão utilizado na plataforma $\mathrm{X} 8$

traseira). Esta separação foi necessária para aumentar o acesso para a montagem do motor na parte traseira e dos sensores na parte dianteira. Na parte inferior dianteira foram colocadas duas varetas de fibra de carbono medindo $14 \mathrm{~cm}$ de comprimento por $1 \mathrm{~mm}$ de espessura por $3 \mathrm{~mm}$ de altura para aumentar a resistência frontal da plataforma em caso de colisão, conforme mostra a figura 16.

Outra mudança estrutural foi o aumento da altura do winglet de 16 para $26 \mathrm{~cm}$ (Fig. 16). O winglet é uma extensão da ponta da asa usada para diminuir o vortex de vento na extremidade da asa, causando menor diferença de pressão no topo e abaixo da asa diminuindo o arrasto da plataforma e, consequentemente, gerando um voo com curvas mais estáveis. Por outro lado, o winglet aumenta a dificuldade de pouso em vento cruzado.

Estudos realizados por Dagur et al. (2018) e Hamada et al. (2018) mostram a eficiência da 


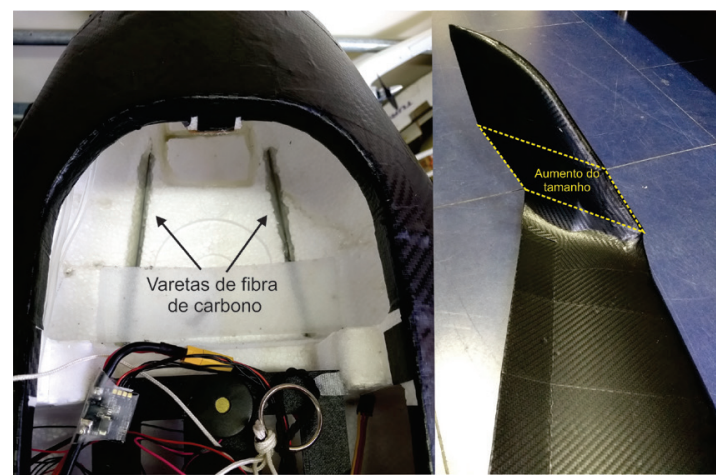

Figura 16. Fixação de varetas de fibra de carbono na estrutura frontal inferior da plataforma X8 e aumento do tamanho original do winglet

colocação do winglet nas extremidades da asa diminuindo o arrasto em torno de $2,1 \%$ se comparado a mesma asa sem winglet.

Foi feita a substituição da placa de plástico original que liga as asas com o corpo central da plataforma, por uma placa de plástico com densidade de $100 \%$ produzida por impressora 3D (Fig. 17). Esta substituição foi necessária visto que a placa original não possui uma junção perfeita e este material demonstrou ser de pouca resistência. A fabricação destas junções foi feita por uma impressora 3D construída peça por peça pelo bolsista Rodrigo Felipe Wiebbelling, um dos autores deste trabalho. Esta impressora possui área útil de impressão de 20×20×20 cm, altura mínima da camada é de 0,2 $\mathrm{mm}$ com largura do filamento de saída em $0,4 \mathrm{~mm}$, sendo o plástico aquecido em $200^{\circ} \mathrm{C}$.

A colocação de adesivo vinílico por ar aquecido na superfície da plataforma aumentou a resistência mecânica e a eventuais cortes no EPO. Este adesivo também diminuiu o atrito da plataforma gerada por superfícies irregulares e promoveu uma melhora na estética.

A plataforma X8 com o winglet de tamanho original e sem o revestimento do adesivo vinílico podem ser visualizados na figura 18.

\section{Equipamentos auxiliares e logística de campo}

\section{Catapulta}

A plataforma X8 com todos os equipamentos e mais baterias possui um peso aproximado de $5,5 \mathrm{~kg}$ e, devido a isso, não pode ser lançada a mão, pois não possui uma velocidade inicial mínima para a decolagem. Portanto, foi adotado para a decolagem

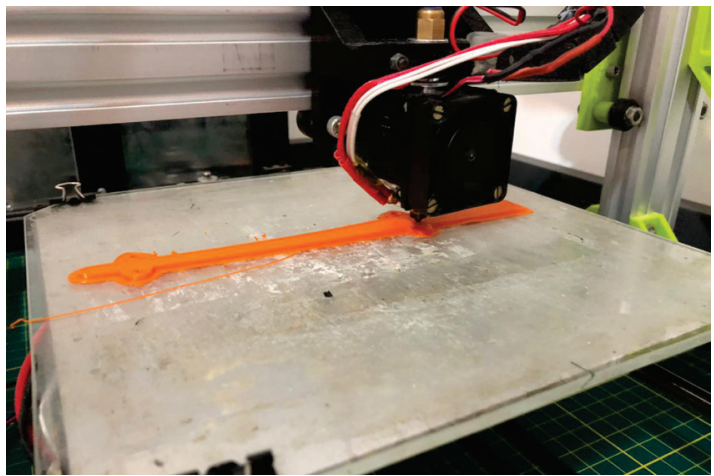

Figura 17. Fabricação e substituição do encaixe da asa por peças de impressora 3D

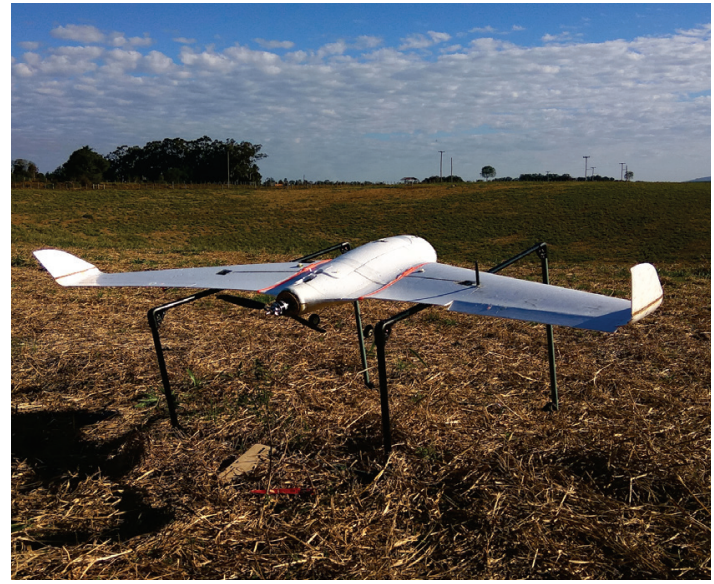

Figura 18. Plataforma X8 pré-modificações, posicionada na catapulta

o sistema de catapulta por elástico. Este equipamento consiste em uma estrutura em cano de PVC e fibra de carbono, no qual a plataforma X8 fica acima com um ângulo de lançamento de 12 graus. Possui um acionador de pedal que libera o gatilho para que o conjunto de elásticos possa puxar a plataforma por um gancho na sua parte inferior, o que confere uma velocidade mínima de decolagem de $28 \mathrm{~km} / \mathrm{h}$. No entanto, algumas modificações foram feitas para que a plataforma X8 pudesse ser colocada. Foram aumentadas as distâncias laterais e a altura do chão em relação ao modelo comprado em loja. Este sistema é mostrado na figura 18.

\section{Tenda gazebo e mesa}

Alguns equipamentos auxiliam na montagem $\mathrm{e}$ execução dos trabalhos de levantamento em campo, sendo o gazebo importante para estabelecimento da base, provendo proteção ao sol e intempéries. Outro exemplo é a mesa de campo, que auxilia na montagem dos equipamentos e monitoramento do voo pelo computador (Fig. 19). 


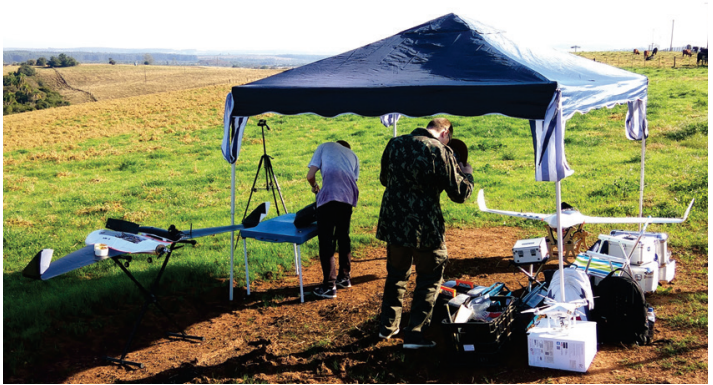

Figura 19. Base de campo composta por gazebo $3 \times 3$ m e mesa auxiliar

\section{Hardware e Software recomendados}

O hardware recomendado fica restrito ao computador, que é utilizado para as configurações da controladora de voo e acompanhamento do voo em campo. Este computador deve ter bom processamento, boa autonomia de baterias e que seja confiável para ser transportado para as etapas de campo. Devido à grande variedade de modelos e fabricantes, são sugeridas as seguintes configurações mínimas:

1. Processador: $8^{\mathrm{a}}$ geração do Processador Intel ${ }^{\circledR}$ Core $^{\mathrm{TM}}$ i7-8750H;

2. Memória RAM: 16GB, DDR4, 2666 MHz;

3. Bateria: 4 células de $56 \mathrm{Wh}$;

4. Placa de vídeo: NVIDIA® GeForce® GTX 1050 Ti com GDDR5 de 4 GB;

5. Disco rígido: Drive primário SSD de 256 GB + disco rígido de 1 TB (5400 RPM);

6. Tela: LED HD antirreflexo.

O principal software utilizado é o Mission Planner, que consiste em um projeto APM de fonte aberta compatível somente com o Windows. É utilizado para o gerenciamento da controladora de voo de veículos autônomos, planejamento de voo, análise do $\log$ de voo e execução com uma interface interativa, criando um simulador em tempo real. A figura 20 mostra plano de voo pré-determinado.

\section{Custo completo da plataforma}

O valor dos equipamentos, sensores e peças sobressalentes, é na sua grande maioria cotada em dólar devido à necessidade de importação dos equipamentos utilizados. As descrições dos equipamentos são mostradas na tabela 1 e não estão incluídos o custo de envio (frete), taxas alfandegárias e impostos.

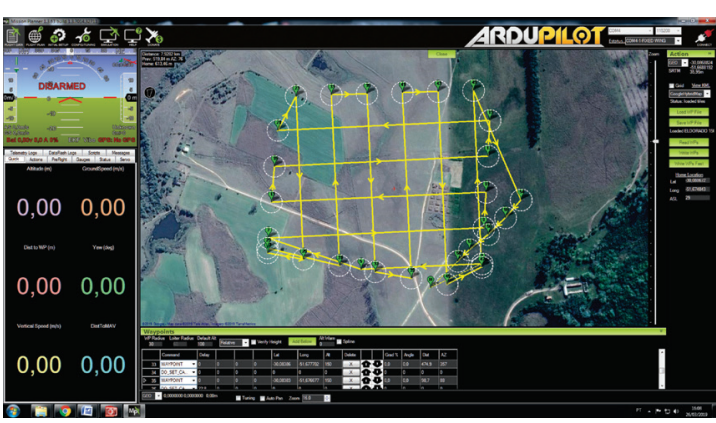

Figura 20. Plano de voo da plataforma X8 com o Software Mission Planner

\section{Conclusões}

Este artigo apresenta uma metodologia de desenvolvimento e montagem de VANT de asa fixa com baixo custo (U\$ 4.070) e de média complexidade de construção e manutenção de expressiva redução de custos quando comparado aos equipamentos similares vendidos no mercado.

A diminuição de recursos destinados à compra de equipamentos, via projetos de fomento nos últimos anos, colaborou de forma significativa para a realização deste trabalho. Além disso, o desenvolvimento da plataforma de acordo com a sua demanda, seja no ensino ou pesquisa otimiza a configuração de melhor custo/benefício.

A plataforma X8 pode ser utilizada por universidades, estabelecimentos de pesquisa e órgãos governamentais em interesse público na forma de monitoramento e obtenção de dados em desastres naturais, desabamento de encostas e barragens, reconhecimento e vigilância.

Como exemplo de aplicações podemos destacar entre inúmeras outras a utilização deste modelo proposto em mapeamento geológico com a utilização de câmeras RGB e/ou multiespectrais podendo gerar dados sobre contatos geológicos em áreas de difícil acesso, identificação de maciços rochosos e posteriormente cálculos de cubagem e de área em zonas mineiras. Nos estudos de sensoriamento remoto pode ser utilizado na geração de dados sobre saúde de florestas e áreas de preservação por meio de suas características espectrais. Devido a estas características, esta plataforma pode ser utilizada no monitoramento da qualidade do ar por meio de sensores específicos e monitoramento e identificação de plumas de contaminação sendo em água ou solo.

Nas últimas décadas o Brasil se tornou um dos principais exportadores de alimentos do mundo. O sistema apresentado, está cada vez mais sendo utilizado na agricultura de precisão. Atuando no 
Tabela 1. Lista dos equipamentos necessários para a montagem de uma plataforma Skywalker X8

\begin{tabular}{|c|c|c|c|c|}
\hline EQUIPAMENTO & ESPECIFICAÇÃO & QUANTIDADE & PREÇO U\$ & ONDE COMPRAR \\
\hline Skywalker X8 & $212 \times 75 \mathrm{~cm}$ & 1 & 149,9 & $2^{*}$ \\
\hline $\begin{array}{c}\text { Motor PROPDRIVE v2 } \\
4258\end{array}$ & $500 \mathrm{kV} / 1200 \mathrm{~W}$ & 1 & 41,53 & $1^{*}$ \\
\hline Hélice fixa & Plástico 12×6" & 2 & 7,48 & $1 *$ \\
\hline Hélice dobrável TGS & Plástico 12×6,5" & 2 & 19,62 & $1 *$ \\
\hline Hélice dobrável & Carbono $14 \times 8 "$ & 2 & 29,8 & $1 *$ \\
\hline Hélice dobrável & Carbono $15 \times 10^{*}$ & 2 & 34,38 & $1 *$ \\
\hline Bateria 4000 mAh & $6 S 35-70 \mathrm{C}$ & 4 & 285,04 & $1 *$ \\
\hline Bateria 5000 mAh & $6 S 35-70 \mathrm{C}$ & 4 & 348,96 & $1 *$ \\
\hline $\begin{array}{r}\text { Carregador/bal- } \\
\text { anceador }\end{array}$ & $2 \times 300 \mathrm{~W}$ & 1 & 127,63 & $1 *$ \\
\hline \multicolumn{5}{|l|}{ Turnigy Reaktor } \\
\hline Rádio (TX) Turnigy 9X & $\begin{array}{c}\text { c/ módulo } 2.4 \mathrm{GHz}, \\
100 \mathrm{~mW}\end{array}$ & 1 & 65 & $1 *$ \\
\hline Módulo FrSKY & $900 \mathrm{MHz}, 1000 \mathrm{~mW}$ & 1 & 61,66 & $5 *$ \\
\hline Servo 939MG & $12,5 \mathrm{~g}$ & 4 & 25,72 & $1 *$ \\
\hline Servo DS339MG & $32 \mathrm{~g}$ & 2 & 16,64 & $1 *$ \\
\hline Paraquedas & $3 \mathrm{~kg}$ & 1 & 74,9 & $2 *$ \\
\hline Paraquedas & $5 \mathrm{~kg}$ & 1 & 91,9 & $2 *$ \\
\hline $\begin{array}{c}\text { Controladora de voo } \\
\text { Pixhawk } 4\end{array}$ & $\begin{array}{r}32 \mathrm{Bit}, 216 \mathrm{MHz} \text { e } \\
512 \mathrm{~KB} \mathrm{RAM}\end{array}$ & 1 & 170 & $6 *$ \\
\hline GNSS Ublox Neo-M8N & 72 canais, $10 \mathrm{~Hz}$ & 1 & 19,99 & $1 *$ \\
\hline $\begin{array}{c}\text { Sensor de velocidade e } \\
\text { pressão do ar }\end{array}$ & Digital, tubo de Pitot & 1 & 54,95 & $1 *$ \\
\hline Telemetria HKPilot v2 & $915 \mathrm{MHz} / 100 \mathrm{~mW}$ & 1 & 34,66 & $1 *$ \\
\hline Telemetria RFD900+ & $900 \mathrm{MHz} / 1000 \mathrm{~mW}$ & 1 & 219,56 & 3* \\
\hline $\begin{array}{c}\text { Câmera RGB Canon } \\
\text { A2400 }\end{array}$ & $16 \mathrm{MP}$ & 1 & 215 & $4^{*}$ \\
\hline Catapulta & & 1 & 24,5 & $1 *$ \\
\hline Gazebo & $3 \times 3 \mathrm{~m}$ & 1 & 90,48 & $7 *$ \\
\hline Mesa dobrável & $0,69 \times 0,69 \mathrm{~m}$ & 1 & 24,56 & $7 *$ \\
\hline Bastão de cola quente & $\mathrm{kg}$ & 1 & 10,34 & $7 *$ \\
\hline $\begin{array}{c}\text { Vinil adesivo fibra de } \\
\text { carbono }\end{array}$ & $\mathrm{m} 2$ & 2 & 15,51 & $7 *$ \\
\hline Notebook & & 1 & $1.809,00$ & 7* \\
\hline Custo Total em U\$ & & & $4.068,71$ & \\
\hline
\end{tabular}

monitoramento de pragas nas lavouras, na elaboração de dados para fornecimento de mapas de diversos índices de vegetação. Auxiliam o produtor na identificação de zonas de baixo rendimento propiciando assim, a atuação em pontos específicos, reduzindo custos de produção e insumos.

Tecnicamente, este trabalho irá incentivar pesquisadores, alunos e responsáveis por elaboração de políticas públicas a desenvolver plataformas de asa fixa especificamente para a sua demanda. Portanto, capacitando cada vez mais o desenvolvedor nos conhecimentos das áreas de geociências, especificamente em geologia, ecologia, biologia, informática e processamento. Uma das principais dificuldades encontradas na montagem do VANT foi a necessidade de importação de todas as peças e componentes, visto que no Brasil não há empresas desenvolvedoras de peças similares. Outra difi- 
culdade encontrada foi a configuração correta da controladora de voo na execução do voo autônomo, nos comandos de acionamento do paraquedas e acionamento da câmera fotográfica.

Mudanças estruturais foram necessárias, uma vez que o kit Skywalker X8 mostrou-se frágil, principalmente nas placas de plástico das junções das asas com o corpo da plataforma. A colocação das varetas de fibra de carbono na parte frontal interna absorveu e dissipou o estresse sofrido pela plataforma em choques frontais, diminuindo o dano ocorrido pelos impactos. O aumento do tamanho dos winglets permitiu um voo mais suave, mas aumentou a deriva lateral da plataforma em ventos cruzados, o que pode gerar imagens oblíquas à direção do voo adquiridas pela câmera. A colocação do adesivo vinílico aumentou a resistência do EPO a rasgos, promoveu a dissipação do estresse sofrido por impactos e diminuiu a resistência do ar em voo.

\section{Agradecimentos}

Ao Conselho Nacional de Desenvolvimento Científico e Tecnológico - CNPq Edital Universal 2012 - pelo financiamento do projeto/processo $\mathrm{n}^{\mathrm{O}}$ 480579/2012-1.

\section{Referências}

Chao, H., Cao, Y., \& Chen, Y. (2010). Autopilots for Small Unmanned Aerial Vehicles: A Survey. International Journal of Control, Automation, and Systems.
8(1): 36-44. doi: 10.1007/s12555-010-0105-z.

Dagur, R., Singh, V., Grover, S., Sethi, N., \& Arora, B. B. (2018). Design of Flying Wing UAV and Effect of Winglets on its Performance. International Journal of Emerging Technology and Advanced Engineering. 8. 414-428.

Hamada, A., Sultan, A., \& Abdelrahman, M. (2018). Design, Build and Fly a Flying Wing. Athens Journal of Technology and Engineering. Vol. 5, Issue 3. 223-250.

Hobbyking. URL:<https://hobbyking.com>. Acesso: 17.07.2018.

Longhitano, G. A. (2010). VANTs para sensoriamento remoto: aplicabilidade na avaliação e monitoramento de impactos ambientais causados por acidentes com cargas perigosas. Dissertação de mestrado. São Paulo: Escola Politécnica da Universidade de São Paulo. 148p.

Madhavan, R., Silva, T., Farina, F., Wiebbeling, R., Renner, L. \& Prestes, E. (2018). Unmanned Aerial Vehicles for Environmental Monitoring, Ecological Conservation, and Disaster Management In: Technologies for Development. ( $1^{\text {st }}$ ed., pp. 31-39). Springer International Publishing. IBSN: 9783319910673.

Medeiros, A. F. (2007). Desenvolvimento de um veículo aéreo não tripulado para aplicação em agricultura de precisão. Dissertação de mestrado. Universidade Federal de Santa Maria. 122p.

Traub, L., W. (2016). Optimal Battery Weight Fraction for Maximum Aircraft Range and Endurance. Journal of Aircraft. 1-3. doi: 10.2514/1.C033416.

Renner, L., Silva J. A. A., Bruch, A. F., Cirolini, A., Ronchi, L. H.; Tisot, D. A.. Gomes da Silva, L. H. \& Mattos, M. S. (2014). Uso de aerofotomosaico adquirido por VANT aplicado na quantificação do volume de pilhas em mineração. In: $47^{\circ}$ Congresso Brasileiro de Geologia, 2014, Salvador. 